\title{
Trends in pacemaker mode prescription 1984-1994: a single centre study of 3710 patients
}

Rajesh K Aggarwal, Simon G Ray, Derek T Connelly, David S Coulshed, Richard G Charles

\begin{abstract}
Objective-To evaluate trends in pacemaker mode prescription from 1984 to 1994 with particular reference to the changes in pacemaker mode prescription for patients aged 80 years and older at implant.

Design-Prospective evaluation of indications for pacing and pacemaker mode prescription in all patients undergoing new pacemaker implantation from 1992 to 1994. Comparison with retrospectively obtained data for patients paced from 1984 to 1991.

Setting-Tertiary referral cardiothoracic centre.

Patients-Group 1: 2622 patients paced at one centre and entered into the national pacing database from 1984 to 1991 . Group 2: 1088 consecutive patients paced from 1992 to 1994.

Results-Use of atrial (AAI) and dual chamber (DDD) pacemakers increased progressively in patients of all ages from 1984 to 1994. There was an increase in the proportion of patients aged 80 years and older from $25 \cdot 4 \%$ (group 1) to $40.5 \%$ (group 2). Patients of all ages in group 2 were more likely to receive DDD units for atrioventricular block (odds ratio (95\% confidence interval) (CI) $9 \cdot 0(7 \cdot 0$ to $11 \cdot 5)$ ) and AAI or DDD units for sinus node disease (odds ratio $(95 \% \mathrm{CI}) 11 \cdot 0(7 \cdot 7$ to $15 \cdot 8)$ ) than those in group 1 . Elderly patients (age $\geqslant 80$ at implant) with atrioventricular block or sinus node disease and a suitable atrial rhythm were less likely to receive DDD or AAI pacemakers than younger patients in both groups.

Conclusions-Use of atrial and dual chamber pacing modes has increased substantially in patients of all ages over the last decade. Although elderly patients represent an increasing proportion of the paced population, they remain less likely to receive atrial or dual chamber pacemakers than younger patients.
\end{abstract}

(Heart 1996;75:518-521)

Keywords: pacemaker mode prescription; physiological pacing and age; audit
The United Kingdom continues to lag behind North America and most western European countries in both pacemaker implant rates and use of atrial and dual chamber pacemakers. ${ }^{12}$ There are wide regional variations in the use of dual chamber pacemakers within the United Kingdom ${ }^{3}$; evidence also exists that elderly patients are less likely to have dual chamber pacemakers implanted than younger patients. ${ }^{4}$ Although such differences have been highlighted following publication of national recommendations for pacemaker mode prescription, ${ }^{5}$ data relating pacemaker mode prescription to patient age are not generally publicised. To evaluate the trends in pacemaker mode prescription for elderly patients in Merseyside, we audited the pacemaker mode prescription according to age at implant for all patients paced at our institution, a large tertiary referral cardiac centre serving a population of $2 \cdot 8$ million, from 1984 to 1994 .

\section{Patients and methods}

From April 1992 to January 1994, we prospectively collected data for all patients undergoing their first endocardial pacemaker implant at our centre. At the time of operation, a standard implant form was completed by the cardiologist and cardiac technician recording patient characteristics, and clinical and electrocardiographic (ECG) indications for pacing and pacemaker mode prescribed. All data were subsequently entered into a computerised database. Similar data were obtained retrospectively from the United Kingdom national pacing database for patients paced at our centre from 1984 to 1991 .

Pacemaker mode prescription was analysed according to patient age and year of implant for all patients. The symptomatic and ECG indications for pacing and pacing mode employed were compared for patients paced from 1984 to 1991 (group 1) with those paced from 1992 to 1994 (group 2). Further comparisons were made between elderly patients (age 80 years or older at implant) and younger patients within each group.

\section{STATISTICAL ANALYSIS}

Data are reported as proportions and were compared using odds ratios and $95 \%$ confidence intervals (CI). The $\chi^{2}$ test (with Yates' 
Table 1 Primary symptomatic indication for pacing

\begin{tabular}{|c|c|c|}
\hline \multirow[b]{2}{*}{ Symptom } & \multicolumn{2}{|l|}{ No of patients } \\
\hline & $\begin{array}{l}\text { Group } 1 \\
(1984-1991) \\
(n=2622)\end{array}$ & $\begin{array}{l}\text { Group 2 } \\
(1992-1994) \\
(n=1088)\end{array}$ \\
\hline $\begin{array}{l}\text { Syncope } \\
\text { Presyncope } \\
\text { Bradycardia } \\
\text { Prophylaxis } \\
\text { Heart failure } \\
\text { Unspecified }\end{array}$ & $\begin{array}{l}965(36 \cdot 8) \\
697(26 \cdot 6) \\
161(6 \cdot 1) \\
154(5 \cdot 9) \\
149(5 \cdot 7) \\
496(18 \cdot 9)\end{array}$ & $\begin{array}{c}445(40 \cdot 9) \\
338(31 \cdot 1) \\
127(11 \cdot 7) \\
61(6 \cdot 5) \\
81(7 \cdot 4) \\
36(3 \cdot 3)^{\star}\end{array}$ \\
\hline
\end{tabular}

correction where appropriate) was used to calculate $\mathrm{p}$ values.

\section{Results}

PATIENT CHARACTERISTICS

Data were available for 3710 patients who had new endocardial pacemaker implantation at our centre from 1984 to 1994,2622 were paced between 1984 and 1991 (group 1) and 1088 paced between April 1992 and January 1994 (group 2). Six hundred and sixty five $(25.4 \%)$ patients in group 1 were aged 80 years or older at implant. This proportion increased significantly to $40.5 \%(n=441)$ in group $2(P<0.0001)$. The median age at implant increased from 74 years in 1984-1991 to 77 years in 1992-1994. Assuming a stable catchment population, the new pacemaker implant rate increased from $\sim 135 /$ million/ annum in 1984-1991 to $\sim 222 /$ million/annum in 1992-1994 $(\mathrm{P}<0.001)$.

\section{INDICATIONS FOR PACING}

Primary symptomatic indication for pacing was similar in the two groups (table 1). Most patients were paced for either syncope or presyncope $(63.4 \%$ in group 1 , and $72 \%$ in group $2)$. The proportion of patients with an "unspecified" symptomatic indication was larger in group $1(18.9 \%)$ than in group 2 $(3.3 \%) \quad(P<0.0001)$. ECG indication for pacing was also similar in the two groups. Atrioventricular block and sinus node disease were the most common diagnoses, accounting for more than $70 \%$ of patients in both groups.

Table 2 ECG indication for pacing

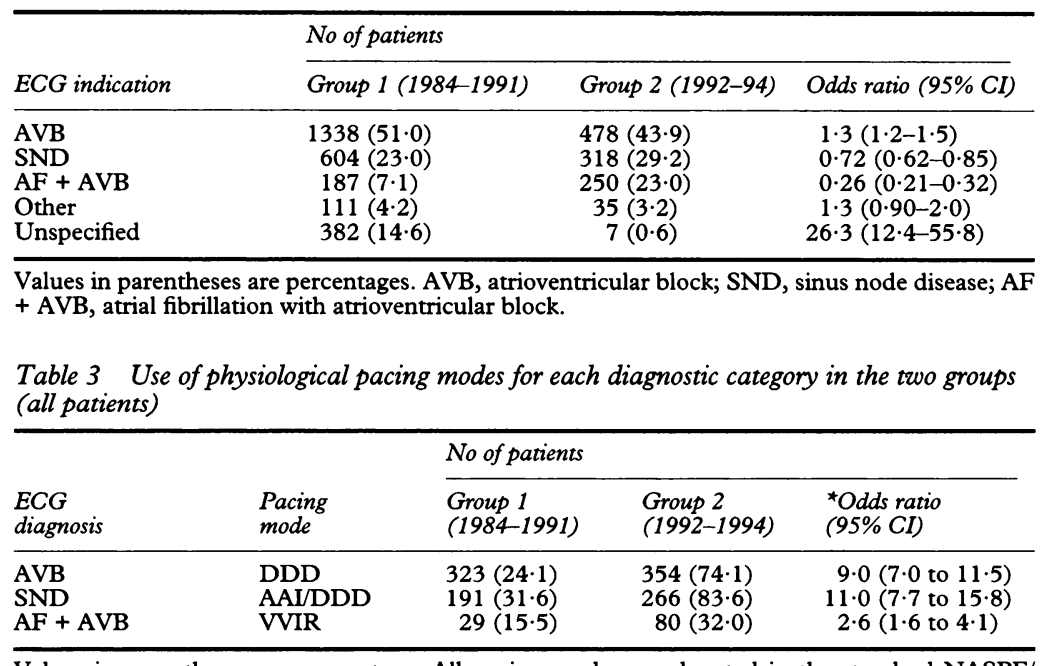

Values in parentheses are percentage. All pacing modes are denoted in the standard NASPE

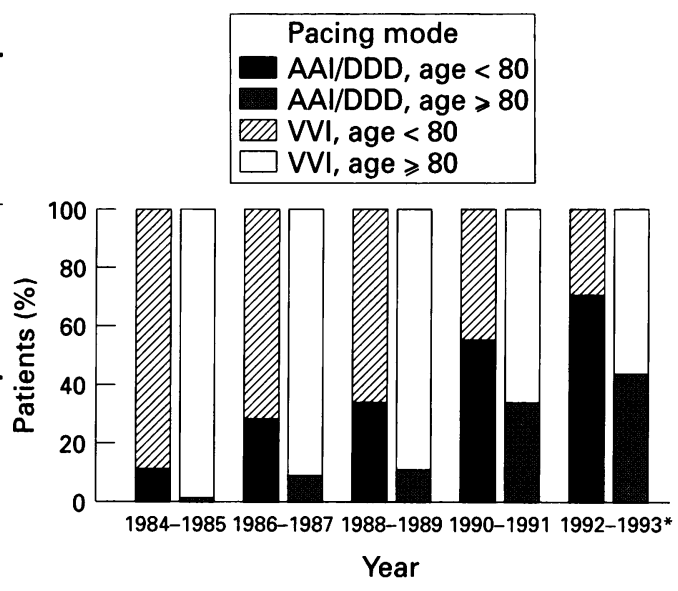

Figure 1 Pacemaker mode prescription by year of implant: comparison of elderly (age $\geqslant 80$ at implant) with younger patients. *Data for 1992-1993 include patients paced in Fanuary 1994.

Fewer patients in group 1 had chronic atrial fibrillation with atrioventricular block $(7 \cdot 1 \%)$ compared with group $2(23 \%)$ and a significantly larger proportion had an "unspecified" ECG diagnosis $(14.6 \% v 0.6 \%)(P<0.0001)$ (table 2).

\section{PACEMAKER MODE PRESCRIPTION}

During the 10 year period 1251 (33.7\%) pacemakers implanted were dual chamber, 111 (3.0\%) atrial single chamber, and 2348 $(63.3 \%)$ ventricular single chamber. There was a steady increase in the use of AAI and DDD pacing modes during this period (fig 1). Patients paced from 1992 to 1994 were considerably more likely to receive atrial or dual chamber systems $(649(59 \cdot 7 \%)$ of 1088$)$ than patients paced from 1984 to 1991 (713 $(27 \cdot 2 \%)$ of 2622$)$ (odds ratio (95\% CI) 4.0 $(3.4$ to 4.6$)(\mathrm{P}<0.0001)$.

From 1992 to $1994,77.9 \%$ of patients with atrioventricular block or sinus node disease and a suitable atrial rhythm received atrial or dual chamber systems compared with $26.5 \%$ of such patients paced from 1984 to 1991 (odds ratio $(95 \% \mathrm{CI}) 9.8(8.0$ to 11.9$) \mathrm{P}<$ 0.0001 ) (table 3). Rate responsive ventricular (VVIR) systems were prescribed for $32.0 \%$ of patients with chronic atrial fibrillation and

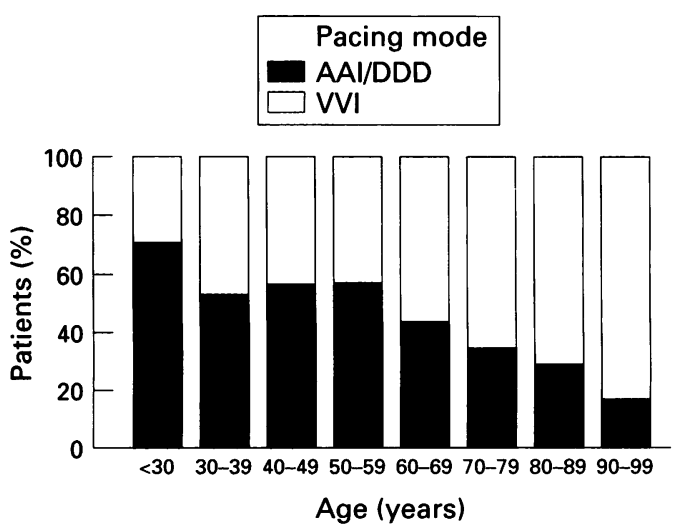

Figure 2 Pacemaker mode prescription 1984-1994 according to patient age. 
Table 4 Age related use of physiological pacing modes: comparison of patients aged 80 years and older at implant with younger patients within each group

\begin{tabular}{|c|c|c|c|c|}
\hline $\begin{array}{l}\text { ECG } \\
\text { diagnosis }\end{array}$ & $\begin{array}{l}\text { Pacing } \\
\text { Mode }\end{array}$ & $\begin{array}{l}\text { Age } \geqslant 80 \\
\text { at implant }\end{array}$ & $\begin{array}{l}\text { Age }<80 \\
\text { at implant }\end{array}$ & $\begin{array}{l}\text { Odds ratio } \\
\text { (95\% CI) }\end{array}$ \\
\hline \multicolumn{5}{|l|}{ Group 1 (1984-1991) } \\
\hline AVB & DDD & $43(15 \cdot 4)$ & $280(26 \cdot 5)$ & $0.50(0.35-0.72)$ \\
\hline SND & AAI/DDD & $31(22 \cdot 0)$ & $160(34 \cdot 6)$ & $0.53(0.34-0.83)$ \\
\hline $\mathrm{AF}+\mathrm{AVB}$ & VVIR & $6(11 \cdot 1)$ & $23(17 \cdot 3)$ & $0.60(0.23-1.56)$ \\
\hline \multicolumn{5}{|l|}{ Group 2 (1992-1994) } \\
\hline AVB & DDD & $121(57 \cdot 3)$ & $233(87 \cdot 3)$ & $0.20(0.12-0.31)$ \\
\hline SND & AAI/DDD & $63(67)$ & $203(90 \cdot 6)$ & $0.21(0.11-0.39)$ \\
\hline $\mathrm{AF}+\mathrm{AVB}$ & VVIR & $20(16 \cdot 8)$ & $60(45 \cdot 8)$ & $0.24(0.13-0.43)$ \\
\hline
\end{tabular}

Values in parentheses are percentages. All pacing modes are denoted in the standard NASPE BPEG generic (NBG) code. ${ }^{6}$ Abbreviations as given in table 2 .

atrioventricular block in 1992-1994 compared with $15.5 \%$ in $1984-1991$ (odds ratio $(95 \%$ CI) $2.6(1.6$ to $4 \cdot 1) \mathrm{P}=0.0001)$.

AGE RELATED CHANGES

Prescription of AAI and DDD pacing systems during the entire study period decreased with advancing age (fig 2). The substantial increase in prescription of AAI and DDD systems over the decade was, however, evident in elderly (age $\geqslant 80$ at implant) as well as younger patients, (fig 1). Nonetheless, elderly patients paced from 1984 to 1991 were less likely to have DDD implants for atrioventricular block and AAI or DDD implants for sinus node disease than younger patients and this difference persisted in those paced from 1992 to 1994 (table 4). For atrial fibrillation with atrioventricular block, elderly patients paced from 1992 to 1994 were significantly less likely to receive VVIR systems $(16.8 \%)$ than younger patients $(45.8 \%)$ paced during the same period $(\mathrm{P}<0.0001)$. During the period 1984 to 1991 , this difference between elderly $(11 \cdot 1 \%)$ and younger patients $(17 \cdot 3 \%)$ did not achieve significance $(P=0 \cdot 40)$.

\section{Discussion}

This audit demonstrates the substantial increase in prescription of physiological pacing modes for patients of all ages undergoing new pacemaker implantation at our institution over the last decade. The findings are in keeping with our progressive pacing policy, reflecting cumulative evidence in the literature which favours physiological pacing. ${ }^{7-18}$ Publication of national recommendations for pacemaker mode prescription in $1991^{5}$ may also have acted as a catalyst, further increasing the use of physiological pacing modes.

Widespread prescription of physiological pacemakers has been criticised in recent years for several reasons, most notably the lack of prospective randomised studies confirming the superiority of physiological pacing and the perceived cost and complexity of implanting and following up such systems. ${ }^{34}$ While results of large scale prospective randomised trials are awaited, it would be unwise to completely ignore the existing evidence favouring atrial pacing for sinus node disease $\mathrm{e}^{11-15}$ and dual chamber pacing for atrioventricular block. ${ }^{16-18}$ Furthermore, the high immediate hardware cost of physiological pacing systems ${ }^{19} 20$ does not indicate a lack of cost effectiveness as such information is not available; concerns about the complexity of such systems are also largely unfounded. ${ }^{21}$

\section{PHYSIOLOGICAL PACING AND AGE}

Recently, attention has been drawn to doctors' reluctance to refer elderly patients for some cardiological investigations and treatment, particularly for coronary artery disease..$^{22}$ Ageism in pacing has also been decried as being unjustified, ${ }^{24}$ however, data relating pacemaker mode prescription to age are not widely publicised. Published reports generally refer to the steady rise in numbers of patients of all ages undergoing cardiological intervention. ${ }^{25}$ This may be appropriate for evaluating access to surgical treatment of coronary artery disease or valvular disease but fails to reveal the potential for covert ageism in cardiac pacing as implanting a VVI pacemaker may abolish syncope caused by sick sinus syndrome but clearly does not constitute optimal treatment.

Opponents of physiological pacing for elderly patients have advocated an arbitrary cut off of 75 years for the use of dual chamber systems as a means of reducing costs. ${ }^{19} \mathrm{We}$ do not subscribe to such a policy which would discriminate against an increasingly large proportion of the paced population $(60 \%$ of new implants at our centre are in patients aged 75 years or older). There is little convincing argument why the elderly should not benefit from physiological pacing as much as younger patients. Indeed, the need for preserved atrial transport may be of greater importance in the elderly, given the greater prevalence of ventricular dysfunction with advancing age. Moreover, evidence supporting physiological pacing for sinus node disease and atrioventricular block in the over 75 age group is continuing to accumulate from prospective randomised studies..$^{15} 18$

In our series, the very highly significant increase in the use of physiological pacing modes in 1992-1994 compared with that in 1984-1991 was evident in patients of all ages. The overall increase in dual chamber pacing for atrioventricular block (with a suitable atrial rhythm) was over $200 \%$ and that in atrial or dual chamber pacing for sinus node disease more than $160 \%$. In both these categories, the relative increase in use of physiological pacing modes for patients aged 80 years or older at implant was even greater than for younger patients. However, elderly patients were significantly less likely to receive physiological pacemakers than younger patients in 19841991 and this difference persisted in the 1992-1994 group. Such differences are likely to be substantially greater in most other implanting centres in the United Kingdom. Although age related use of dual chamber pacemakers is not widely publicised, data from one large implanting centre in 1992 showed that only $41(13 \cdot 1 \%)$ of 313 patients aged 75 years and older had dual chamber pacemakers implanted compared with $126(90 \cdot 6 \%)$ of 139 patients aged under 75 years at implant (odds ratio $(95 \% \mathrm{CI}) 0.016(0.008$ to 0.030$), \mathrm{P}<$ $0 \cdot 0001){ }^{4}$ 
STUDY LIMITATIONS

Retrospectively acquired data (for 1984-1991) are likely to be less accurate than the prospective data for patients paced from 1992 to 1994. This is reflected by the substantially fewer patients with "unspecified" symptomatic and ECG indication for pacing from 1992 to 1994. The significantly larger proportion of paced patients with atrial fibrillation in 1992-1994 than in 1984-1991 may also reflect the greater accuracy of the 1992-1994 data; some of the 1984-1991 patients with atrial fibrillation may have been classed as having atrioventricular block.

In this audit, we did not evaluate the concurrent (non-cardiac) medical problems of paced patients. The increased prevalence of such conditions in elderly patients may account for some of the observed differences in prescription of physiological pacing modes.

\section{CONCLUSIONS}

In summary, there has been a substantial increase in pacemaker implant rates and in prescription of physiological pacing modes in patients of all ages paced at our institution over the last decade. The proportion of paced patients who are aged 80 years and older at implant has also increased considerably during this period. However, even in a centre where a substantially larger proportion of the pacemakers implanted are "physiological" than is the case nationally, elderly patients remain less likely to have physiological systems implanted than younger patients. To some extent, these differences reflect the greater prevalence of associated medical conditions in the elderly which makes the use of sophisticated pacemakers inappropriate. More widespread audit of age related pacemaker mode prescription should be undertaken to assess whether elderly patients are being denied the benefits of such pacemakers solely on the basis of age.

We gratefully acknowledge the invaluable assistance of all the Liverpool Cardiothoracic Centre cardiac technicians with collection of implant data from 1992 to 1994.

1 Bernstein $\mathrm{AD}$, Parsonnet V. Survey of cardiac pacing in the United States in 1989. Am $\mathcal{F}$ Cardiol 1992;69:331-8.

2 Cunningham AD, Rickards AF, Nathan AW. Trends in pacemaker implantation: is the UK the "poor man of Europe"? [abstract]. Br Heart $\mathcal{F}$ 1994; 71 : P59.

3 Petch MC. Who needs dual chamber pacing? BMF 1993; 307:215-6.
4 Channon KM, Cripps TM, Ormerod O. Recommendations for pacing. BMF 1992;305:1431.

5 Clarke M, Sutton R, Ward D, Camm AJ, Rickards A, Ingram $\mathrm{A}$, et al. Recommendations for pacemaker preIngram $A$, et al. Recommendations for pacemaker pre-
scription for symptomatic bradycardia. Report of a workscription for symptomatic bradycardia. Report of a work-
ing party of the British Pacing and Electrophysiology ing party of the British Pacing and
Group. Br Heart $\mathcal{f} 1991 ; 66: 185-91$.

6 Bernstein A, Camm J, Fletcher R, et al. The NASPE/BPEG generic pacing code for antibradyarrhythmia and adaptive rate pacing and antitachycardia devices. $P A C E 1987$; 10:794-9.

7 Kruse I, Arnman K, Conradson TB, Ryden L. A comparison of the acute and long-term haemodynamic effects of ventricular inhibited and atrial synchronous ventricular inhibited pacing. Circulation 1982;65(2):846-55.

8 Ausubel K, Steingart RM, Shimshi M, Klementowicz P, Furman S. Maintenance of exercise stroke volume during ventricular versus atrial synchronous pacing: role of contractility. Circulation 1985;72(5):1037-43.

9 Perrins EJ, Morley CA, Chan SL, Sutton R. Randomised controlled trial of physiological and ventricular pacing. $\mathrm{Br}$ Heart $\mathcal{F} 1983 ; 50: 112-7$.

10 Cohen SI, Frank HA. Preservation of active atrial transport: an important clinical consideration in cardiac pacing. Chest 1982;81:51-4.

11 Rosenqvist M, Brandt J, Schüller H. Long-term pacing in sinus node disease: effects of stimulation mode on cardiovascular morbidity and mortality. Am Heart $\mathcal{f} 1988$; 116:16-22.

12 Hesselson AB, Parsonnet V, Bernstein AD, Bonavita GJ. Deleterious effects of long term single chamber ventricular pacing in patients with sick sinus syndrome: the hidden penefits of dual chamber pacing. $₹ \mathrm{Am}$ Coll Cardiol 1992; 19:1542-9.

13 Rosenqvist $\dot{M}$, Brandt J, Schüller $H$. Atrial versus ventricular pacing in sinus node disease: a treatment comparison lar pacing in sinus node disease: a trea

14 Sutton R, Kenny RA. The natural history of sick sinus syndrome. PACE 1986;9:1110-4.

15 Andersen HR, Thuesen L, Bagger JP, Vesterlund T, Thomsen PEB. Prospective randomised trial of atrial versus ventricular pacing in sick-sinus syndrome. Lancet 1994;344:1523-8.

16 Sulke N, Dritsas A, Bostock J, Wells A, Morris R, Sowton E. "Subclinical" pacemaker syndrome: a randomised study of symptom free patients with ventricular demand (VVI) pacemakers upgraded to dual chamber devices. $\mathrm{Br}$ Heart $\mathcal{f}$ 1992;67:57-64

17 Heldman D, Mulvihill D, Nguyen H, Messenger JC, Rylaarsdam A, Evans $\mathrm{K}$, et al. True incidence of pacemaker syndrome. PACE 1990;13(Pt II):1742-50.

18 Channon KM, Hargreaves MR, Cripps TR, Gardner M, Ormerod OJM. DDD vs. VVI pacing in patients aged over 75 years with complete heart block: a double-blind crossover comparison. $Q \mathcal{F}$ Med 1994;87:245-51.

19 de Belder MA, Linker NJ, Jones S, Camm AJ, Ward DE. Cost implications of the British Pacing and Electrophysiology Group's recommendations for pacing. $B M F$ 1992;305:861-5.

20 Ray SG, Griffith MJ, Jamieson S, Bexton RS, Gold RG. Impact of the recommendations of the British Pacing and Electrophysiology Group on pacemaker prescription and on the immediate costs of pacing in the Northern region. on the immediate costs of pac

21 McComb JM, Bexton RS. Permanent pacemakers and the elderly: concerns, costs and benefits [editorial]. Br Heart $\mathcal{f}$ elderly: concer

22 Northridge D, Hall RJC. Cardiological services for the elderly. $\mathcal{R}$ Coll Physicians Lond 1995;29(1):9-10.

23 Pycock CJ, King A, Marshall AJ. Management of heart disease in the elderly in Plymouth Health District. $\mathcal{F} R$ Coll Physicians Lond 1995;29(1):15-9.

24 Payne GE, Skehan JD. Issues in cardiac pacing: can ageism be justified? [editorial]. Br Heart $\mathcal{f} 1994 ; 72: 102-3$.

25 Lawson-Matthew PJ, Channer KS. Reporting on reportscardiological intervention in elderly patients. $\mathcal{f} R$ Coll Physicians Lond 1995;29(1):11-4. 